\title{
Strengthening impacts of spring sea surface temperature in the north tropical Atlantic on Indian Ocean dipole after the mid-1980s
}

\author{
Guangli Zhang ${ }^{1,7} \cdot$ Xin Wang $^{2,3,4} \odot \cdot$ Qiang Xie ${ }^{1,5,6} \cdot$ Jiepeng Chen ${ }^{2,3} \cdot$ Sheng Chen ${ }^{2,3}$
}

Received: 6 July 2021 / Accepted: 28 December 2021 / Published online: 31 January 2022

(c) The Author(s) 2022

\begin{abstract}
It is well known that the Indian Ocean dipole (IOD) is closely related to El Niño-Southern Oscillation (ENSO). In this study, it is found that spring-summer north tropical Atlantic (NTA) sea surface temperature (SST) anomalies can contribute to the development of the IOD since the mid-1980s as well as ENSO. After the mid-1980s, an anticyclonic circulation over the subtropical northeastern Pacific could be excited by cool NTA SST anomalies in spring and summer due to a Gill-type Rossby-wave response. A low-level cyclonic circulation appears in the west Pacific in turn. The anomalous lower-level southwesterlies on the southeastern flank of the cyclonic circulation reduce the climatological wind speed, and thus, warm SST anomalies appear and extend to the central tropical Pacific via the wind-evaporation-SST (WES) feedback. As a result, Walker circulation over the IndoPacific region is changed, with anomalous descending in the eastern tropical Indian Ocean and ascending in the central tropical Pacific. The descending branch of anomalous Walker circulation generates surface southeasterly wind anomalies along the coast off Sumatra and lifts the thermocline in the eastern tropical Indian Ocean, which produces a positive IOD event in autumn. Such a cross-basin mechanism is supported by a coupled model experiment with warm SST perturbations over the NTA. In contrast, although cold NTA SST anomalies can induce warm SST anomalies in the eastern equatorial Pacific through interhemispheric meridional circulation before the mid-1980s, the responses in the tropical Indian Ocean are rather weak. In addition, the enhancement in the NTA-IOD relationship after the mid-1980s is suggested to result from the changes in the SST mean state under the context of global warming, which is confirmed by two coupled model experiments with different mean SST backgrounds.
\end{abstract}

Keywords Indian Ocean dipole $\cdot$ North tropical Atlantic $\cdot$ Three-ocean interactions · Global warming

Xin Wang

wangxin@scsio.ac.cn

Qiang Xie

gordonxie@idsse.ac.cn

1 Institute of Deep-Sea Sciences and Engineering, Chinese Academy of Sciences, Sanya, China

2 State Key Laboratory of Tropical Oceanography, South China Sea Institute of Oceanology, Chinese Academy of Sciences, Guangzhou, China

3 Southern Marine Science and Engineering Guangdong Laboratory (Guangzhou), Guangzhou, China

4 Innovation Academy of South China Sea Ecology and Environmental Engineering, Chinese Academy of Sciences, Guangzhou, China

5 Laboratory for Regional Oceanography and Numerical Modeling, Pilot National Laboratory for Marine Science and Technology, Qingdao, China

6 Center for Ocean Mega-Science, Chinese Academy of Sciences, Qingdao, China

7 University of Chinese Academy of Sciences, Beijing, China

\section{Introduction}

The Indian Ocean dipole (IOD) is an interannual fluctuation in sea surface temperature (SST) anomalies between the western and eastern tropical Indian Ocean accompanied by equatorial surface wind anomalies (Saji et al. 1999; Webster et al. 1999). It is well documented that the IOD is of great importance in modulating the climate in local and remote regions (Saji and Yamagata, 2003a, b; Guan and Yamagata 2003; Ashok et al. 2003; Abram et al. 2007, 2008; Schott et al. 2009; Cai et al. 2009, 2012; Nuncio and Yuan 2015). Thus, the understanding of the IOD mechanism and prediction has received more attention in the community.

The IOD could be trigger by external forcing out of the Indian Ocean and internal forcing within the Indian Ocean (Yang et al. 2015). For external forcing, more attentions are paid on the roles of El Niño-Southern Oscillation (ENSO), which can influence the IOD through Walker circulation (e.g. Baquero-Bernal et al. 2002; Xie et al. 2002; Annamalai 
et al. 2003; Li et al. 2003; Behera et al. 2006; Wang and Wang 2014) or Indonesian Throughflow (Yuan et al. 2011, 2013). Compared to many researches on the impacts of the tropical Pacific, less study focuses on the relationship between the Atlantic and IOD. Kucharski et al. $(2008,2009)$ and Wang et al. (2009) indicated that the warm SST in the Atlantic Niño region can induce an atmospheric Kelvin wave, which triggers surface easterly wind anomalies in the tropical Indian Ocean and promotes generation of the IOD. However, Wang et al. (2019) pointed out that the processes for an Atlantic Niño inducing a positive IOD need to be further confirmed.

Recently, the influences of the tropical Atlantic on global climate are paid more and more attentions (Cai et al. 2019; Wang 2019). According to analyzing model outputs, Wang et al. (2014) found that the weak simulated Atlantic meridional overturning circulation is associated with cold SST biases in the entire North Hemisphere and warm SST biases in the Southern Hemisphere. Based on observational data and experiments, a triggering effect of spring north tropical Atlantic (NTA) SST anomalies on central type ENSO in the following seasons is identified (Ham et al. 2013; Ding et al. 2017; Wang et al. 2017). Ham et al. (2017) revealed that tropical Atlantic SST warming can induce lower-level easterly wind anomalies in the western Pacific and decrease rainfall over the off-equatorial western Pacific through modulating global Walker circulation. Kim et al. (2017) indicated that Atlantic multidecadal oscillation (AMO) and Pacific Decadal Oscillation (PDO) phases can modulate the tropical Pacific mean state and then drive ENSO-induced convection to the northwest Pacific. Some studies explored the influences of Atlantic SST on the Indian Ocean. For examples, cool SST anomalies in the NTA can trigger Kelvin waves as well as Atlantic Niño events and induce cooling in the North Indian Ocean (Yu et al. 2016). NTA warming in the decay spring of El Niño may partially contribute to the second warming of the North Indian Ocean in the following summer by Gill-type response (Ma et al. 2020). Several researches emphasized that the warmer Atlantic SST in recent decades can modulate the linkages of global tropical oceans. Park et al. (2019) indicated that the Atlantic warm pool SST-ENSO correlation is intensified after the mid-1980s. Wang et al. (2017) pointed out that the warmer NTA SST since the early-1990s has provided a favorable background state for enhancing biennial variability in the Pacific. The recent warming of SST in the Atlantic intensifies the Walker circulations over the Indo-Pacific region by strengthening Pacific trade winds (McGregor et al. 2014) and warms the Indo-western Pacific through wind-evaporation-SST (WES) mechanism (Li et al. 2016).

Although the connections between the tropical Atlantic and Indian Ocean climates have been discussed in previous studies, the responses of the IOD to the climate systems in the tropical Atlantic are still an open issue. The purpose of the present study is to discover which and how climate mode in the tropical Atlantic could impact the IOD except for Atlantic Niño. The rest of paper is organized as follows. The datasets, methods and models used in the study are introduced in Sect. 2. Section 3 shows the relationship between the NTA SST anomalies and the IOD and its change on interdecadal timescales. Based on the observation and model simulations, the physical processes and mechanism of how the NTA SST anomalies influence the IOD are presented in Sect. 4. Section 5 discusses why the relationship between the NTA SST anomalies and the IOD is enhanced after the mid-1980s. Finally, a summary and discussion are given in Sect. 6.

\section{Datasets and methods}

Since observational datasets are more reliable after the mid-twentieth century (Wang and Wang 2014), situations after 1950 are concentrated in the present study. Monthly SST from 1950 to 2018 was adopted from the Extended Reconstructed Sea Surface Temperature (ERSST) version 5 (Huang et al. 2017), which has a spatial resolution of $2^{\circ} \times 2^{\circ}$. The atmospheric reanalysis dataset of horizonal wind, vertical velocity and sea level pressure (SLP) comes from the National Centers for Environmental Prediction-National Center for Atmospheric Research (NCEP-NCAR) Reanalysis 1 (Kalnay et al. 1996), which spans from 1950 to 2018 with a horizontal resolution of $2.5^{\circ} \times 2.5^{\circ}$ and 17 vertical levels. The $20^{\circ} \mathrm{C}$ isotherm is used to denote the depth of the thermocline, which comes from the Institute of Atmospheric Physics Global Ocean Temperature (IAP, Cheng et al. 2017). The linear trends are removed, and all anomalies are calculated as the departures from the 1950-2018 climatology.

The dipole mode index (DMI) proposed by Saji et al. (1999) is constructed by the difference in SST anomalies in the western tropical Indian Ocean $\left(50^{\circ}-70^{\circ} \mathrm{E}, 10^{\circ} \mathrm{S}-10^{\circ} \mathrm{N}\right)$ and the southeastern tropical Indian Ocean $\left(50^{\circ}-70^{\circ} \mathrm{E}\right.$, $\left.0^{\circ}-10^{\circ} \mathrm{S}\right)$. The positive/negative IOD events are defined as the normalized DMI value exceeding \pm 1 standard deviation (std) are listed in Table 1. An NTA index is defined by the standardized SST anomalies averaged in the North Tropical Atlantic $\left(60^{\circ}-20^{\circ} \mathrm{W}, 0^{\circ}-20^{\circ} \mathrm{N}\right)$ shown in the black box in Fig. 1a.

To investigate the connection between the NTA SST anomalies and IOD, several numerical experiments are conducted in the study by using the Community Earth System Model (CESM) version 1.2.2, which is an advanced earth system model with interactive components of the atmosphere, ocean, land and sea ice (Hurrell et al. 2013). The atmospheric component used in the present study is Community Atmosphere Model version 4 (CAM4) with a $1.9^{\circ} \times 2.5^{\circ}$ horizontal resolution and 26 vertical levels. 
Table 1 The IOD events during 1950-1985 and 1986-2018

\begin{tabular}{lcc}
\hline & $1950-1985$ & $1986-2018$ \\
\hline Positive IOD & $19611963^{+} 1972 * 19821983^{+}$ & $1986^{*} 1994^{*}$ \\
& & 19972002 \\
& & $20062015^{*}$ \\
& & $2018^{*}$ \\
Negative IOD & $1956196019641974 * 1981$ & 19901996 \\
& & $1998^{+} 2005^{+}$ \\
& & $2010^{+} 2016$ \\
\hline
\end{tabular}

+ and * mean the NTA index averaged in March-April-May-JuneJuly (MAMJJ) exceeding 1 and -1 std, respectively

The ocean component is Parallel Ocean Program version 2 (POP2), which has a horizontal resolution of approximately $1^{\circ}$ on the tripolar grid and a maximum depth of $5375 \mathrm{~m}$ vertically divided into 60 levels. The designs of the model experiments are introduced in Sects. 4.2 and 5, respectively.

\section{The NTA-IOD relationship and its interdecadal variation}

To explore the connection between the tropical Atlantic and the occurrence of the IOD, Fig. 1 shows the evolution of regressed SST anomalies during spring to autumn against the boreal fall (September-October-November, SON) DMI. In the tropical Indian Ocean, the significantly cool SST anomalies cover the eastern Indian Ocean basin in boreal spring (March-April-May, MAM, Fig. 1a). The
IOD with the significantly warm SST anomalies in the western Indian Ocean and cooling in the southeastern Indian Ocean emerges during summer (June-July-August, JJA, Fig. 1b) and then reaches its peak in the following September-October-November (SON, Fig. 1c). Before and accompanying the IOD appearance, there are significantly cool SST anomalies in the NTA (Fig. 1a, b). It seems that the SST anomalies in the NTA during spring and summer are closely related to IOD development.

The NTA-IOD relationship is further examined by a 21-year running correlation between the autumn DMI and spring-summer (March-July, MAMJJ) NTA index (Fig. 2). The relationships between the DMI and NTA index experience an interdecadal change around the mid1980s. The running correlations are rather weak before the mid-1980s, while significantly negative relationships are seen after the mid-1980s. The running correlations with different window lengths (e.g., 17, 19, and 23 years) show similar results. This intensified relationship of the Atlantic-Pacific SST after the mid-1980s is also seen in the relationship between the summer Atlantic warm pool (AWP, $100^{\circ} \mathrm{W}-50^{\circ} \mathrm{W}, 5^{\circ} \mathrm{N}-30^{\circ} \mathrm{N}$ ) and the Pacific Meridional Mode (Park et al. 2019). It is noted that the present study focuses on the NTA region during spring-summer, which is to the southeast of the AWP. In addition, the relationships of the NTA-ENSO and ENSO-IOD are checked (figures not shown). The former experiences a similar interdecadal enhancement after the mid-1980s. However, the latter is significant throughout the past decades even if the impacts of the NTA are removed, indicating that the
Fig. 1 Regression maps of SST $\left({ }^{\circ} \mathrm{C}\right)$ anomalies against the September-October-November (SON) DMI during 1950-2018. The dotted regions indicate a 90\% level of confidence based on Student's $t$ test. The black box indicates the location of the North tropical Atlantic (NTA, $0-20^{\circ} \mathrm{N}, 60-20^{\circ} \mathrm{W}$ )

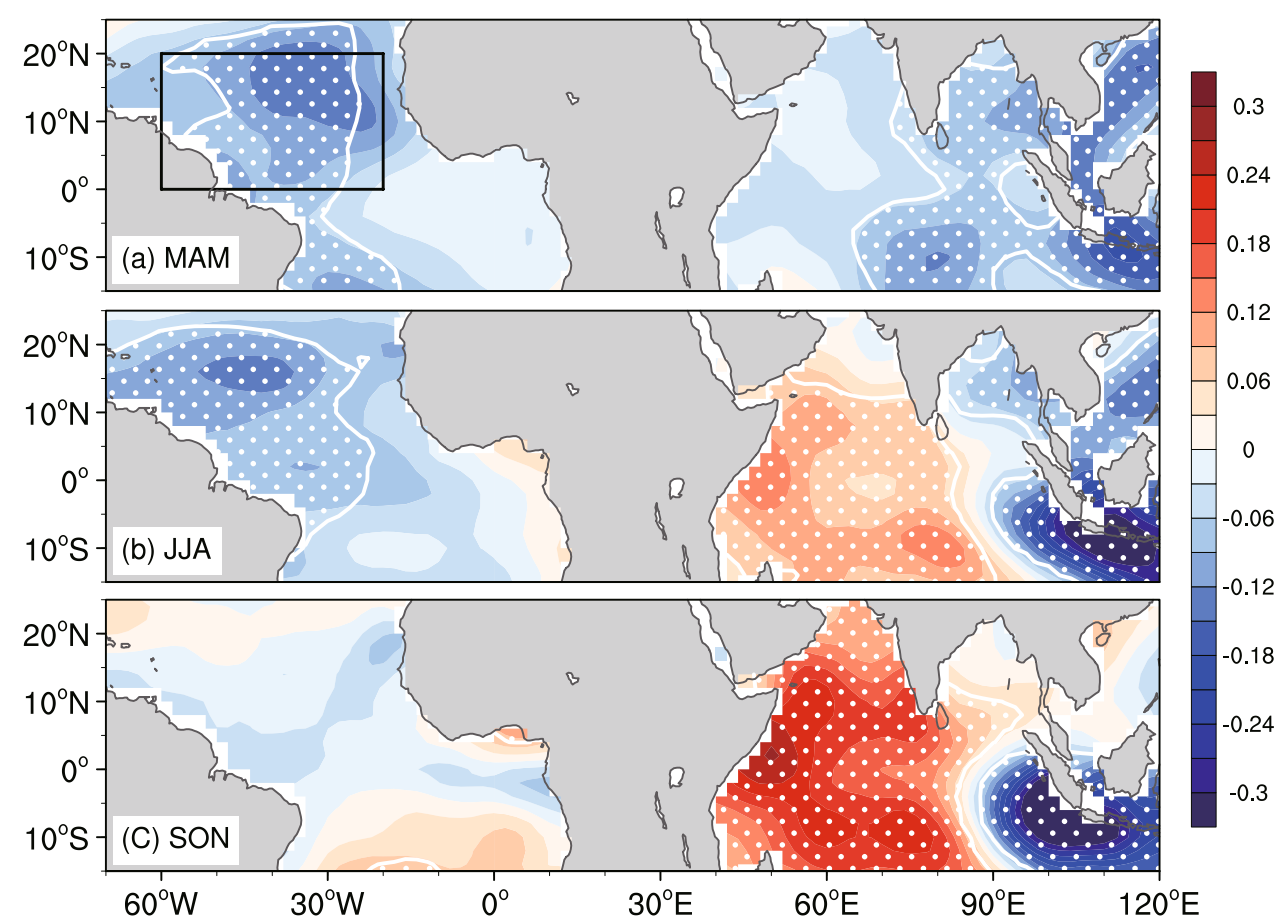


Fig. 2 21-year sliding correlation coefficients between the NTA index averaged in March-April-May-June-July (MAMJJ) and the subsequent SON DMI during 1950-2018. The black dots represent that the correlation coefficients exceed $90 \%$ confidence level

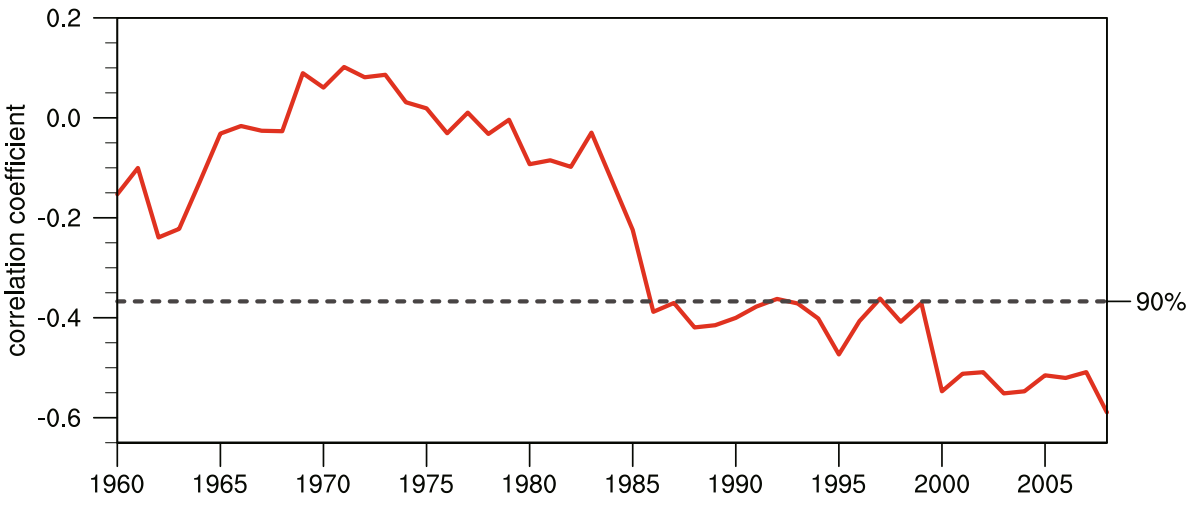

intensified NTA-ENSO relationship can not significantly influence the ENSO-IOD relationship.

In the following, due to interdecadal variation in the relationship between the IOD and NTA index, the physical processes in two periods are investigated and compared. One is before the mid-1980s (1950-1985) with a weak relationship of the IOD-NTA indices, and the other is after the mid-1980s (1986-2018) with a significantly negative relationship.

The specific IOD years during the two periods are listed in Table 1. Associated with these IOD years, the composited SST and lower-level wind anomalies in the two periods are compared in Fig. 3. During boreal autumn, the IOD is seen in both time periods, which features significantly warm SST anomalies in the western Indian Ocean and cool SST anomalies in the southeastern tropical Indian Ocean coupled with significant southeasterly anomalies (Fig. 3c, f). However, the evolutions of the IOD, as well as the large-scale circulations and SST anomalies in the tropical Pacific and Atlantic, show significant differences in two time periods during the IOD development stage (Fig. 3a-e). Before the mid-1980s, weak warm SST anomalies prevailed in the tropical Indian Ocean in spring (Fig. 3a). The warm SST anomalies intensify in the western and central tropical Indian Ocean in summer, while cool SST anomalies appear in the southeastern tropical Indian Ocean, accompanied by strengthened southeasterly anomalies off Sumatra (Fig. 3b). The significant zonal dipole of SST anomalies persists in autumn. In comparison, SST anomalies in spring significantly cooled in the tropical Indian Ocean after the mid-1980s (Fig. 3d). Although the zonal dipole of SST anomalies is seen in summer, the amplitude of the IOD after the mid-1980s is clearly weaker than that before the mid-1980s due to weakly warm SST anomalies in the western tropical Indian Ocean (Fig. 3e). Previous studies have demonstrated interdecadal changes in the IOD in terms of the intensity (Ashok et al. 2004; Annamalai et al. 2005) and peak season (Du et al. 2013). Here, it is suggested
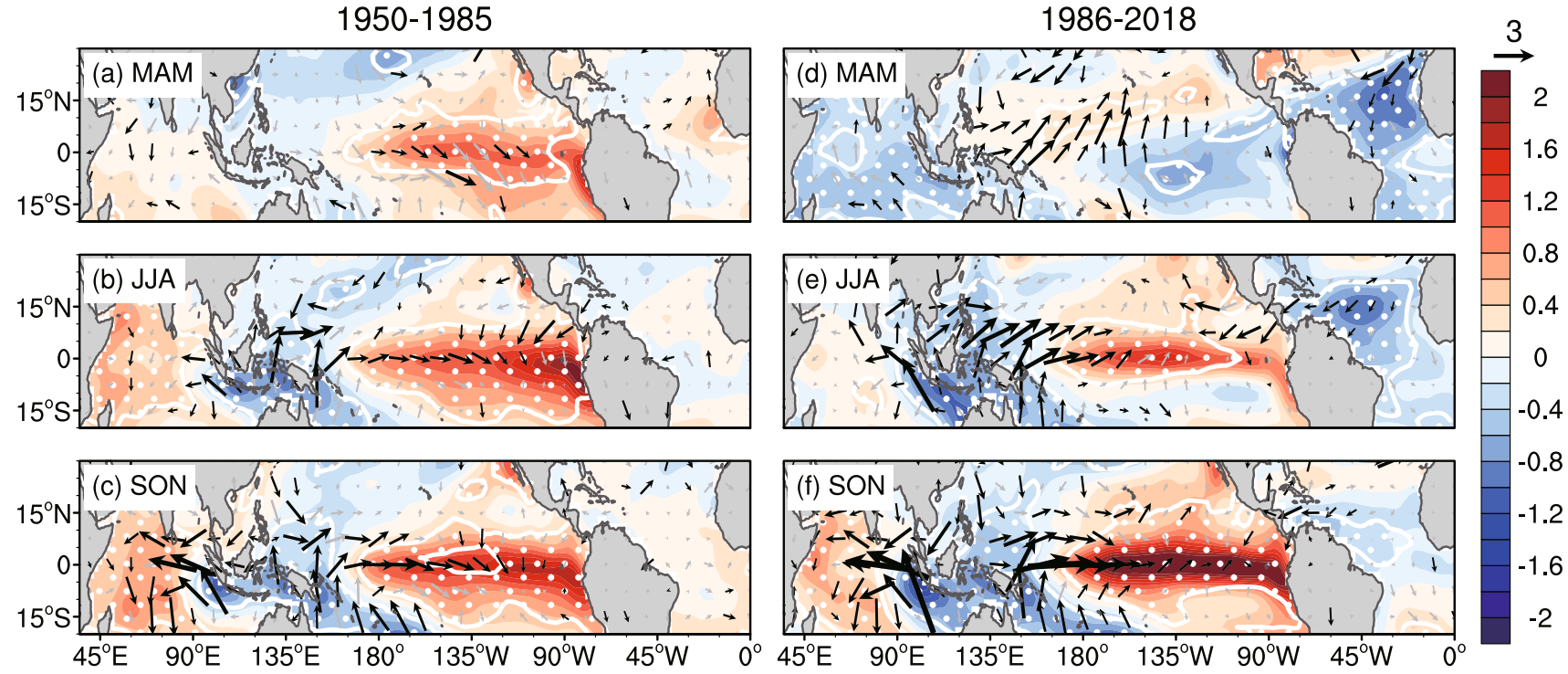

Fig. 3 Seasonal evolutions of composited (positive IOD events minus negative IOD events) SST $\left({ }^{\circ} \mathrm{C}\right.$, shading) and 1000-hPa wind $\left(\mathrm{m} \mathrm{s}^{-1}\right.$, vector) anomalies during a-c 1950-1985 and d-f 1986-2018. The

dotted regions and black vectors indicate confidence levels exceeding $90 \%$ according to Student's $t$ test 
that the evolution of the IOD experienced an interdecadal change around the mid-1980s.

The SST and surface wind anomalies in the tropical Pacific show clear differences during IOD development in the two time periods (Fig. 3). Before the mid-1980s, an El Niño-like pattern is seen in the tropical Pacific from spring to autumn. Significant warm SST anomalies are located in the central and eastern equatorial Pacific, accompanied by anomalous westerlies in the western tropical Pacific (Fig. 3a-c). After the mid-1980s, the significant warm SST anomalies originate in the northeastern subtropical Pacific in spring (Fig. 3d), accompanied by lowerlevel southwesterly winds on their southwest, which is similar to the central Pacific El Niño (Yu and Kao 2007; Kao and Yu 2009) or the El Niño Modoki II (Wang and Wang 2013). The warm SST anomalies in the subtropical northeastern Pacific further strengthen and extend southwestward to the equatorial central Pacific in summer and autumn (Fig. 3e, f) via WES feedback (Vimont et al. 2009; Yeh et al. 2015; Wang et al. 2019; Fang and Yu 2020). Previous studies have pointed out that the different SST patterns over the tropical Pacific in boreal spring and summer could influence the change in the IOD amplitude, especially the intensity of SST anomalies over the southeastern tropical Indian Ocean (Annamalai et al. 2003; Du et al. 2013; Wang and Wang 2014). The distinct SST and wind anomalies over the tropical Pacific in the two periods might be responsible for the interdecadal change in the IOD evolution.

Furthermore, the most distinct differences associated with the IOD are seen in the north tropical Atlantic during the two time periods. Significantly cool SST anomalies occur in the NTA during spring and then gradually decay in summer and autumn after the mid-1980s (Fig. 3d-f), while the change in SST anomalies before the mid-1980s is rather weak (Fig. 3a-c). From Table 1, the positive IOD can follow warm or cool NTA SST anomalies, and one negative IOD appears when the NTA is cool before the mid-1980s, indicating that there is no close connection between the IOD and the NTA SST anomalies during this time period. However, 4 of 7 positive IODs appear with cool NTA conditions, and half of the negative IODs occur with warm NTA after the mid-1980s. It is suggested that the NTA SST anomalies may modulate the IOD appearance as well as ENSO after the mid-1980s.

\section{The mechanism of how the NTA SST anomalies influence the IOD after the mid-1980s}

\subsection{Physical processes of the NTA impacting the tropical Pacific and IOD}

From Fig. 3, the IOD is related to SST anomalies in the equatorial Pacific in both time periods. It is well known that ENSO can influence the SST anomalies in the NTA (Alexander and Scott 2002; Yin and Zhou 2019) and Indian Ocean (Wang and Wang 2014; Yang et al. 2015). Therefore, to clearly address the influences of SST anomalies in the NTA on the IOD, the ENSO-related parts are removed by subtracting the linear regression related to the Niño3.4 index (SST anomalies averaged in $70^{\circ}-120^{\circ} \mathrm{W}, 5^{\circ} \mathrm{S}-5^{\circ} \mathrm{N}$ ). It is suggested that the IOD in the peak season is greatly associated with ENSO, as in spring (Wang and Wang 2014). Therefore, according to the method used by Clark et al. (2000) and Wang et al. (2006), the influence of ENSO in spring is removed as follows:

Variable $_{\text {nonENSO }}=$ Variable $-r<$ Variable,

Niño 3.4 index $>\times$ Niño 3.4 index

where $r$ is the regression coefficient of the variable regressed onto the March-April-May (MAM) Niño3.4 index. Here, all variables and indices are standardized before removing ENSO signals.

After removing ENSO's influences, the seasonal regression of anomalous SST and large-scale atmospheric circulations in the tropical Indian-Pacific-Atlantic against the MAMJJ NTA index scaled by -1 during two time periods are shown in Figs. 4, 5, 6 and 7. Here, the NTA index is multiplied by -1 to display a positive IOD pattern in the regression analysis. The responses in the Pacific and Indian Oceans to the anomalous cool North Atlantic in the two time periods are separately analyzed in the following.

(a) Before the mid-1980s

Accompanied by lower-level northwesterly wind anomalies, warm SST anomalies induced by NTA appear in the south equatorial Pacific near the coast of South America in spring (Fig. 4a). An interhemispheric process is a distinct feature in the time period. Air flows across the equator in the lower troposphere, ascends in the southeastern tropical Pacific and southern tropical Atlantic, and then moves toward the North Atlantic in the upper troposphere (Fig. 5a). The anomalous northerlies crossing the equator in the lower level could turn to westerly wind anomalies due to the Coriolis force in the Southern Hemisphere. This surface northwesterly wind anomaly weakens the climatological trade winds and leads to warm SST anomalies in the Southeastern tropical Pacific, which in turn enhance the meridional circulation. Such oceanic and atmospheric responses in the eastern tropical Pacific induced by the cool North Atlantic are similar to the mechanisms proposed by Wang et al. (2010, 2014). Under the control of meridional circulation, warm SST anomalies in the eastern tropical Pacific could develop in summer and autumn (Fig. 4b, c). However, the Walker circulation linking 

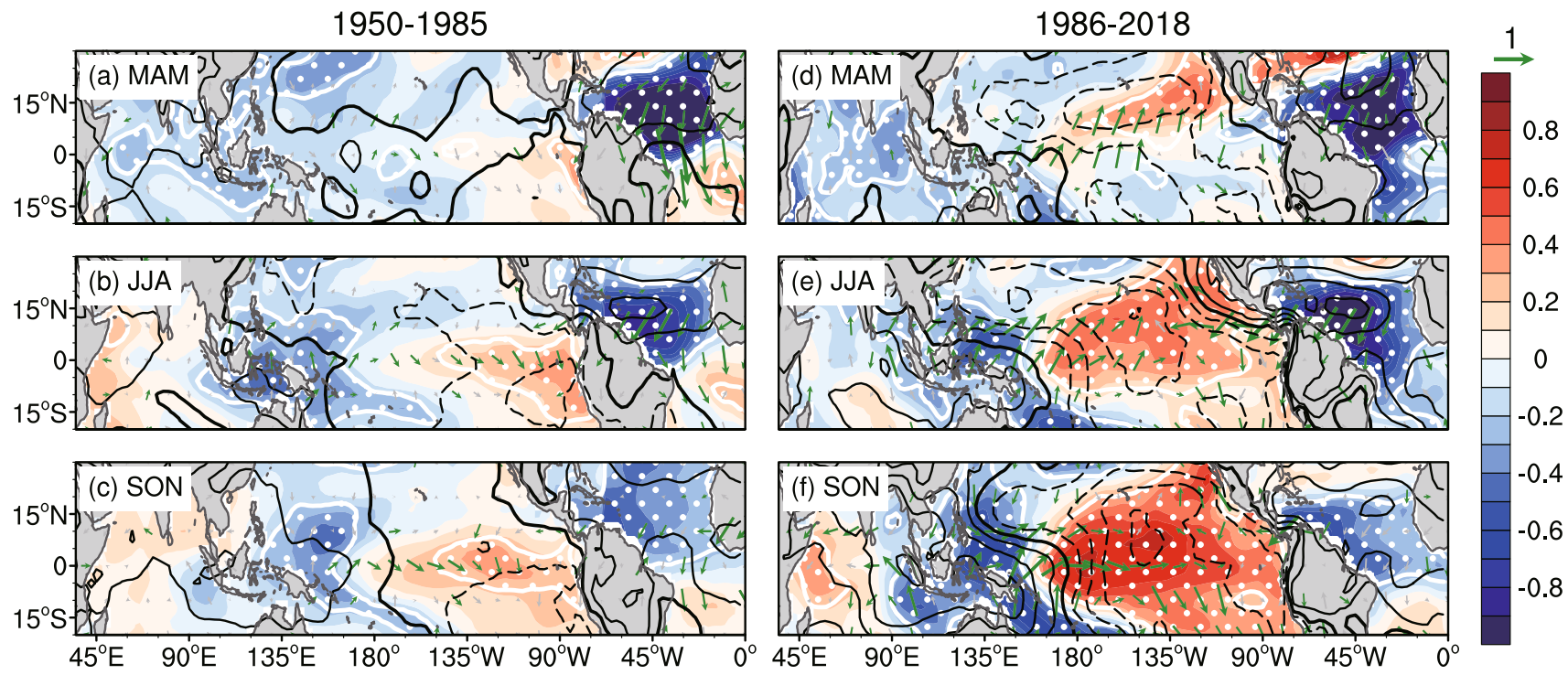

Fig. 4 Regressions of SST (shading), sea level pressure (contour) and $1000-\mathrm{hPa}$ wind anomalies (vector) against the MAMJJ NTA index scaled by -1 during a-c 1950-1985 and d-f 1986-2018. The influences of ENSO in spring are removed in the Indian Ocean and the

Pacific by subtracting linear regression against the MAM Niño3.4 index. The dotted regions and green vectors indicate confidence levels exceeding $90 \%$ based on Student's $t$ test. The thick line indicates the zero contour, and the interval of contours is 0.15
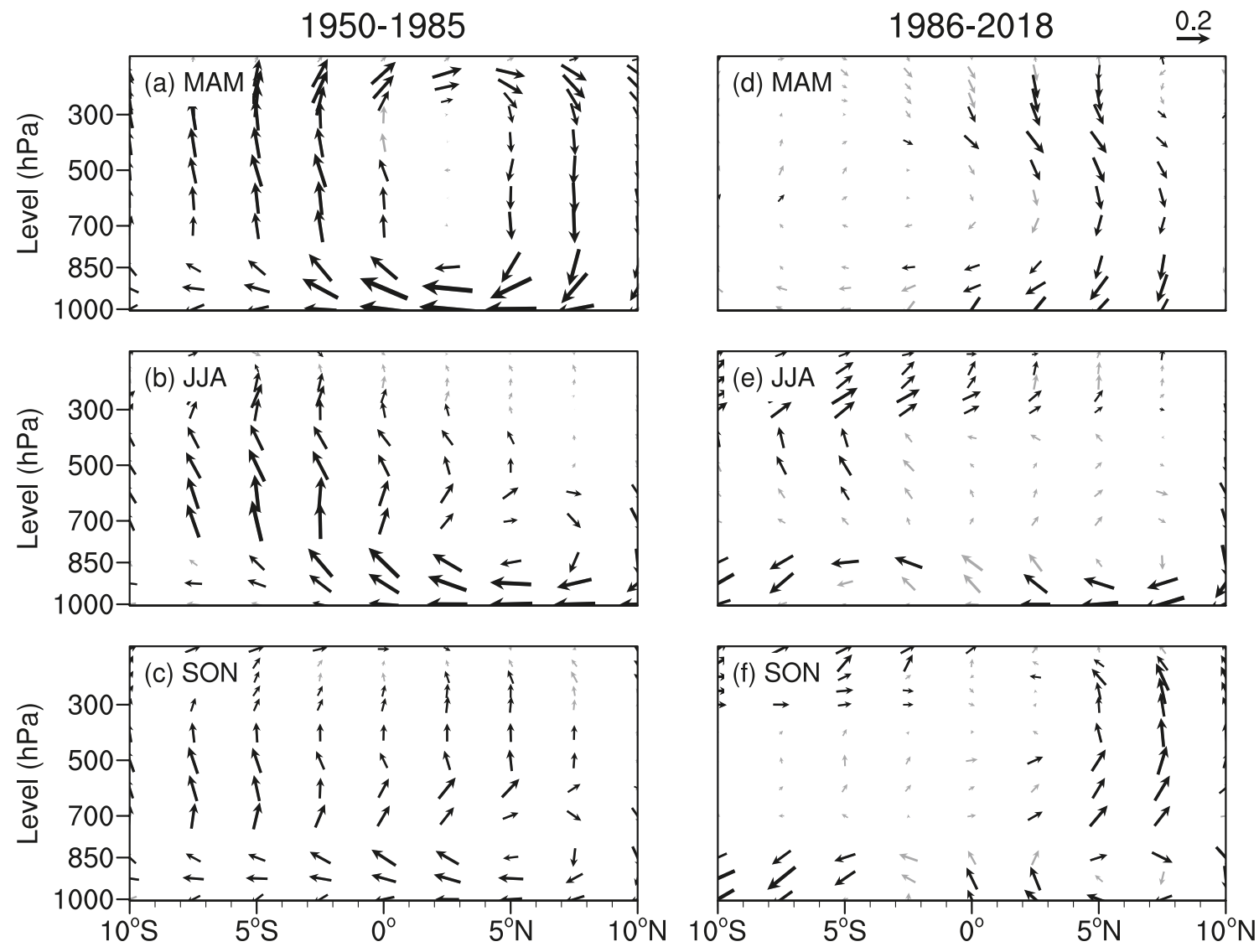

Fig. 5 Regressed meridional circulation anomalies of meridional winds and vertical velocity anomalies (scaled by -1 ) along $150^{\circ}-$ $20^{\circ} \mathrm{W}$ against the MAMJJ NTA index scaled by -1 during a-c 1950-1985 and d-f 1986-2018. The influences of ENSO in spring are removed by subtracting linear regression against the MAM Niño3.4 index. The black vectors mean exceed the $90 \%$ confidence level based on Student's $t$ test 

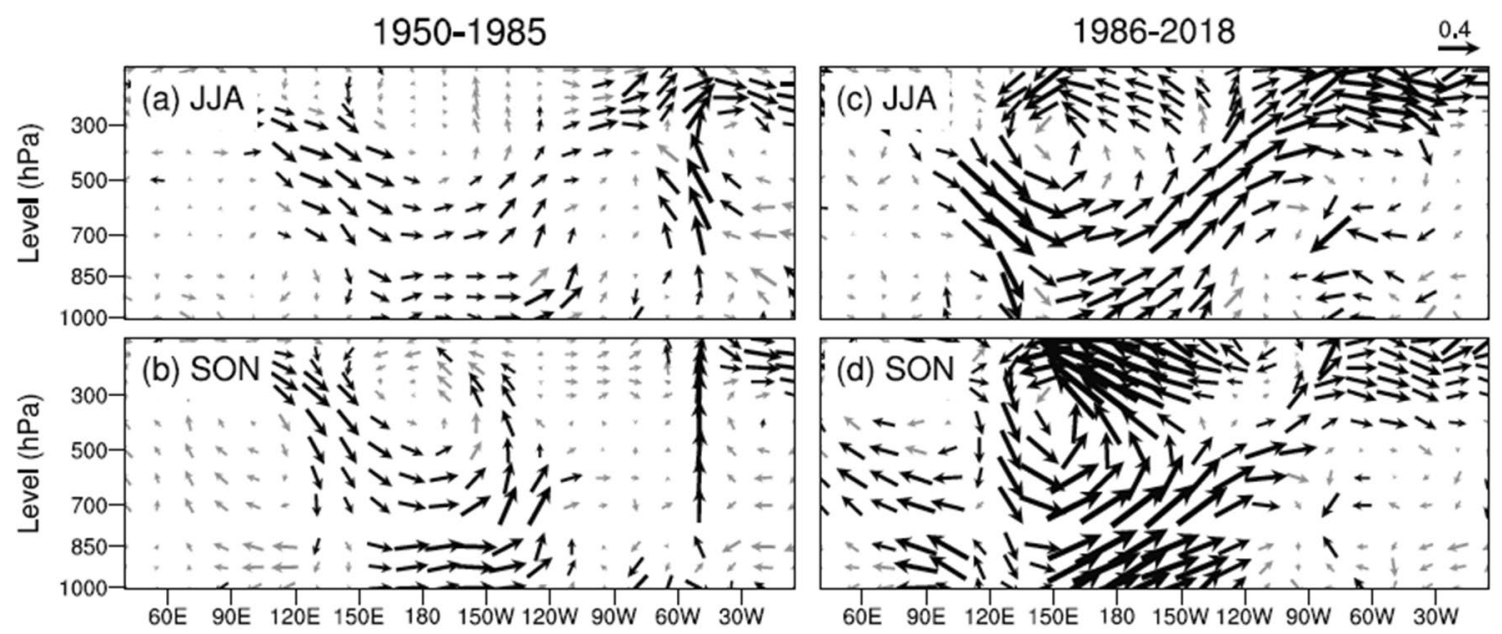

Fig. 6 Regressed equatorial $\left(5^{\circ} \mathrm{S}-5^{\circ} \mathrm{N}\right)$ vertical-zonal circulation anomalies of zonal winds and vertical velocity anomalies (scaled by -1) in boreal summer and autumn against the MAMJJ NTA index scaled by -1 during a, b 1950-1985 and c, d 1986-2018, respec- tively. The influences of ENSO in spring over the Indian Ocean and Pacific $\left(30^{\circ} \mathrm{E}-70^{\circ} \mathrm{W}\right)$ are removed by subtracting linear regression against the MAM Niño3.4 index. The black vectors mean exceeding the $90 \%$ confidence level based on Student's $t$ test
Fig. 7 Longitude-time sections of anomalous thermocline depth $\left(20^{\circ} \mathrm{C}\right.$ isotherm depth) averaged over $10^{\circ} \mathrm{S}-0^{\circ}$ regressed by the MAMJJ NTA index scaled by -1 during a 1950-1985 and b 1986-2018. The influences of ENSO in spring are removed by subtracting linear regression against the MAM Niño3.4 index. The dotted regions indicate values exceeding the $90 \%$ confidence level based on Student's $t$ test

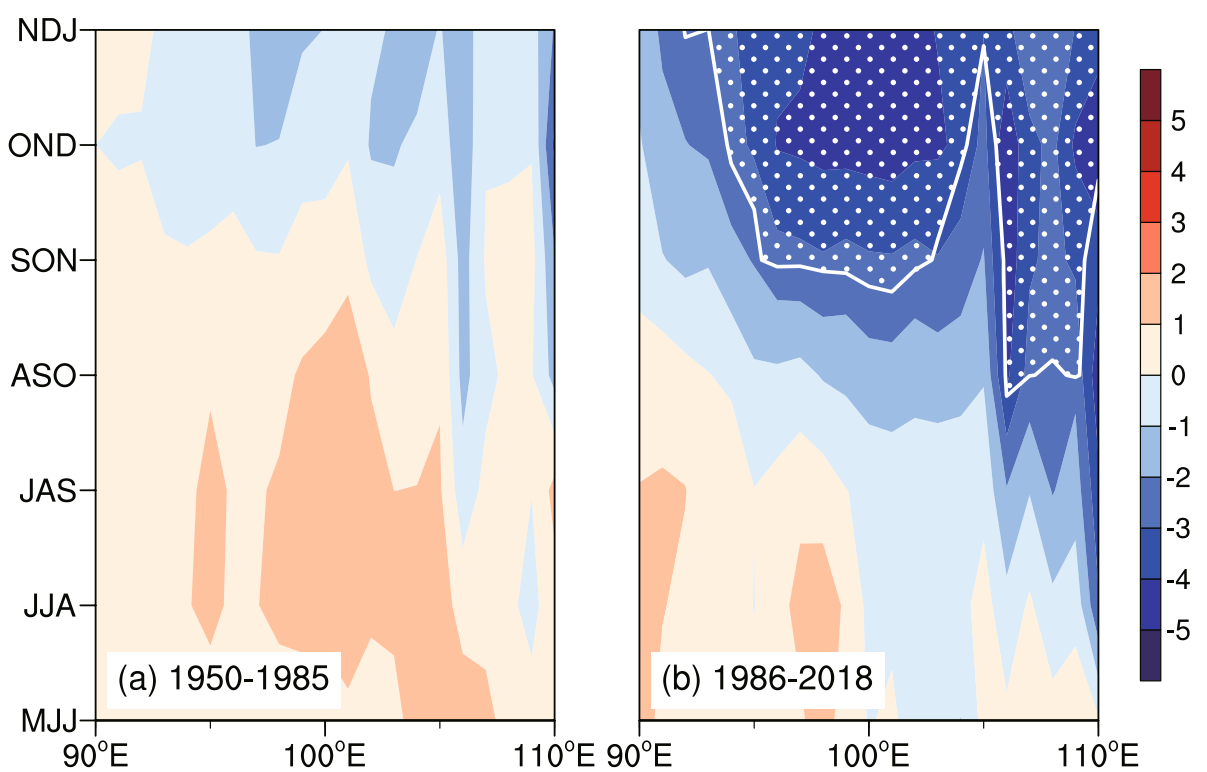

the tropical Pacific and Indian Ocean is rather weak (Fig. 6a, b); thus, significant signals of sea temperature are not found in the Indian Ocean, and no significant IOD appears before the mid-1980s (Figs. 4a-c, 7a).

(b) After the mid-1980s

Significant SST responses to cool NTA SST anomalies after the mid-1980s first appear in the northeastern subtropical Pacific rather than in the southeastern tropical Pacific before the mid-1980s (Fig. 4a, d). This indicates that the physical mechanisms of the NTA influencing the Pacific climate are totally different in two time periods. After the mid-1980s, in response to the negative diabetic heating, an anticyclone circulation occurs over the west of NTA to the subtropical northeastern Pacific. Further to the west of the anti-cyclone due to teleconnection of Rossby-wave response. A cyclonic circulation appears over the subtropical northwestern Pacific in turn, which induce lower-level southeasterly wind anomalies on its southeast flank (Fig. 4d). The southwesterly wind anomalies are overlaid with the climatological northeasterly trade wind and thus decrease the wind speed and sea surface evaporative heat loss in the subtropical Pacific. Through WES feedback (Xie and Philander 1994), southwesterly wind in the north subtropical Pacific warms up SST beneath, and the resultant warm SST anomalies in turn enhance 
the surface wind anomalies. Therefore, the warm SST anomalies become stronger and extend to the tropics from spring to summer (Fig. 4d, e). In addition to result in the anomalous warm SST in the subtropical Pacific, the cyclonic circulations in western Pacific resulting from teleconnection of the Rossby-wave response could induce the westerly wind anomalies in its south flank over the central-western Pacific as earlier as in spring after the mid-1980s (Fig. 4d). The anomalous lower-level westerlies over the central-western Pacific develop since spring (Fig. 4a, e, f). The earlier the westerly wind anomalies are established, the longer the SST warming in the central-east Pacific can develop, favoring stronger responses in tropical SST and atmospheric circulation to the NTA, which leads to significant changes of the Walker circulation over the tropical Pacific and Indian Ocean.

These physical processes are similar to previous results (Ham et al. 2013; Wang et al. 2017; Ding et al. 2017). Different from before the mid-1980s, the interhemispheric processes associated with meridional circulation are not clear after the mid-1980s (Fig. 5d-f). Therefore, it is suggested that the cool SST in the NTA could induce warm SST anomalies in the subtropical and tropical Pacific mainly via Gill-response and WES feedback after the mid-1980s. Through this process, responses of warm SST in the Pacific after the mid-1980s are much stronger than those before the mid-1980s.

The warm SST anomalies in the central-eastern tropical Pacific in summer and autumn after the mid-1980s, which are induced by the anomalous cool NTA SST, are helpful for IOD development via Walker circulation (Baquero-Bernal et al. 2002; Annamalai et al. 2003; Vecchi and Soden 2007; Wang and Wang 2014). Figure 6 illustrates the cross-section of vertical circulation over the equatorial Pacific and Indian Ocean during summer and autumn regressed by the MAMJJ NTA index, which was scaled by -1 . Anomalous zonal circulations over the tropical Atlantic are not well organized and not contribute directly to the connections between the tropical Atlantic and Pacific during both the two periods (Fig. 6). However, after the mid-1980s, air ascends significantly in the eastern equatorial Pacific (east of $150^{\circ} \mathrm{E}$ ) in summer (Fig. 6c) because of the underlying warm SST (Fig. 4e). Due to the ascending motion, an upper-level divergence and associated westward flows at the upper level are in the central equator Pacific. Upper-level convergence and sink motions are seen near $120^{\circ} \mathrm{E}$ (Fig. 6c). The anomalous Walker circulations are enhanced in autumn (Fig. 6d) due to warmer SST anomalies in the central Pacific (Fig. 4f). The sinking branch of the circulation cell can induce lower-level westerly anomalies over the western equatorial Pacific and easterly anomalies over the eastern equatorial Indian Ocean (Figs. 4f, 6d). The anomalous easterlies can increase the upwelling cold subsurface water and lift the thermocline and cool SST near the Sumatra coast by enhancing the thermocline feedback after summer (Fig. 7b), which ensures the development of a positive IOD (Li et al. 2003; Liu et al. 2011).

Based on above analysis, the subtropical northeastern Pacific SST anomalies play an important role in connecting the NTA SST anomalies and the IOD, which could be supported by the relations between the NTA/IOD and subtropical northern Pacific SST anomalies (figures not shown). Since the SST anomalies in the equatorial Pacific which induced by the subtropical Pacific can modulate the IOD via the Indo-Pacific zonal circulation (Figs. 6, 11), the relationships of the subtropical northeastern Pacific-mean SST anomalies with the NTA index and Niño 3.4 index are calculated, which are both intensified after the mid-1980s, while the relationships of the autumn Niño 3.4 index with simultaneous DMI in autumn are stable. These results show the important roles of the subtropical Northern Pacific SST anomalies in the NTA-IOD relationship changes.

\subsection{Simulated impacts of the anomalous NTA SST on the IOD}

To verify the physical processes of the NTA SST anomalies influencing the IOD suggested by the observations, a group of 20-set pacemaker experiments is conducted with a fully coupled general circulation model. The group of sensitivity experiments includes a control run (CTRL_run) and a warm NTA run (NTA_run). Both CTRL_run and NTA_run are implemented with the external forcing fixed at the levels in 2000 for simulating the climate state after the mid-1980s.

After freely coupled running 250 years for spin-up, an additional 30 years are integrated to obtain the climatological SST state globally. In the CTRL_run, the ocean and atmosphere are freely coupled except in the NTA region, where the SST is fixed to the climatological field at every integration step. The NTA_run is configured consensus as the CTRL_run, but SST over the NTA is superimposed with the prescribed positive SST anomalies from January to September. Figure 8 illustrates the imposed positive SST anomalies over the NTA region, which are the composite differences of the SST in warmer and cooler years. The warmer and cooler years are chosen as the values of the MAMJJ NTA index higher/lower than 1/-1 std during 1950-2018. It is noted that the prescribed NTA SST anomalies are as high as $1.8^{\circ} \mathrm{C}$, which is approximately twice the observed SST anomalies. Both the CTRL_run and NTA_run are integrated from the 251 year for another 100 years, and the outputs in the last 20 years that are stabilized are used for ensemblemean analysis. 

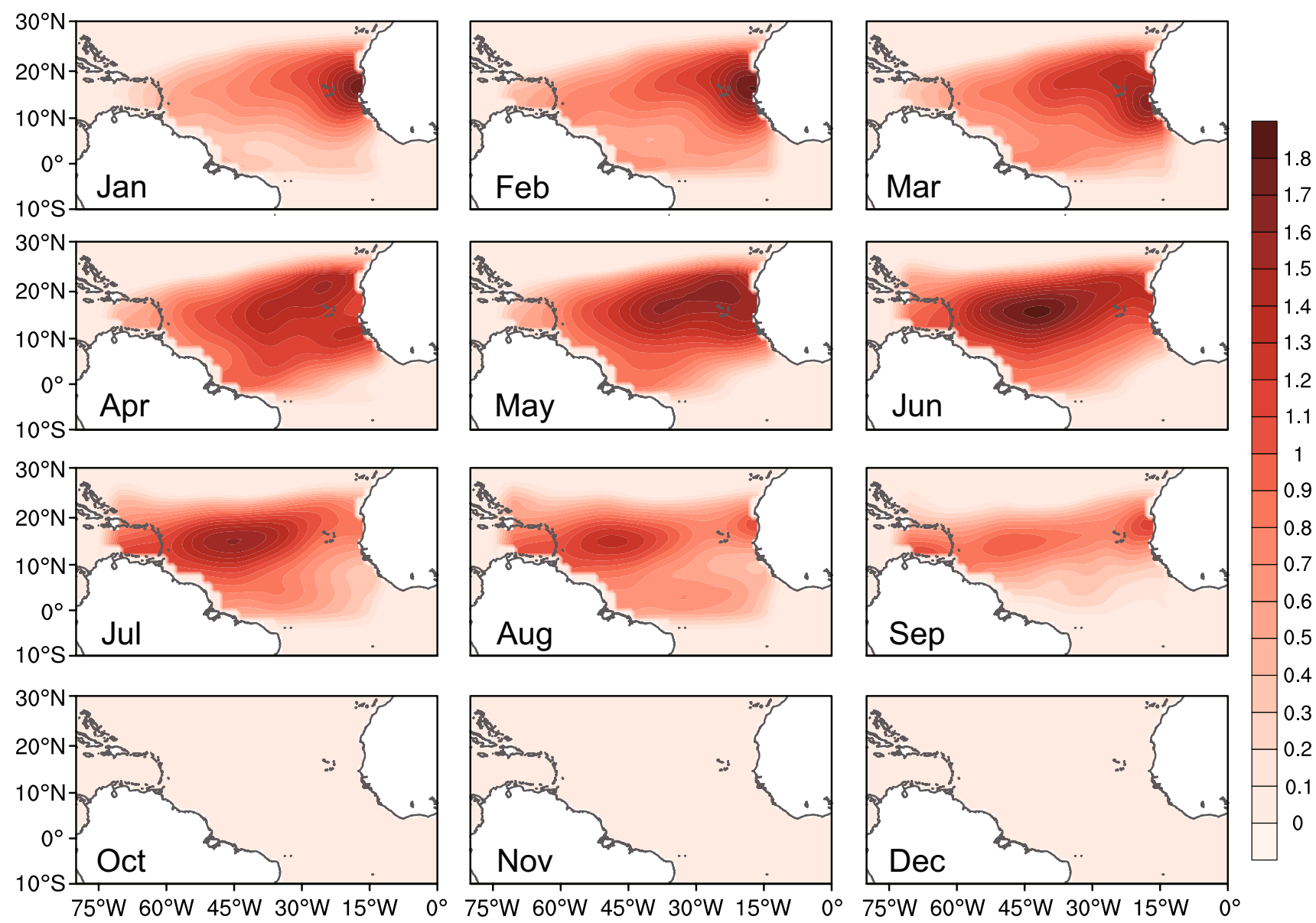

Fig. 8 The prescribed SST anomalies used in NTA_run. These SST anomalies are the composite differences of the SST in warmer and cooler years. The warmer and cooler years are chosen as the values of the MAMJJ NTA index higher/lower than 1/-1 std during 1950-2018

The ensemble differences between the CTRL_run and NTA_run (CTRL_run minus NTA_run) display the responses of SST and lower-level wind anomalies in the tropical Pacific and Indian Ocean to the anomalous negative SST in the NTA region (Fig. 9). During summer, the model results demonstrate an anticyclonic circulation over the subtropical eastern Pacific and a cyclonic circulation over the western subtropical Pacific due to a Gill-type response (Fig. 9a). Between the anticyclonic and cyclonic circulations over the subtropical Pacific, there are strong southwesterly wind anomalies around the central subtropical Pacific accompanied by warm SST anomalies extending from the subtropical Pacific into the tropical Pacific, which are similar to the observations (Fig. 4e). Such responses of SST and surface winds over the subtropical Pacific are consistent with results of (Ham et al. 2013, 2017). Nevertheless, compared with the observed regression results, the warm SST anomalies in the subtropical North Pacific shift westward (Fig. 9), which may be due to the biases of air-sea coupling in the current state-of-the-art models (Lin et al. 2015; Wang et al. 2019). In addition to Gill responses, meridional circulations over the NTA and the eastern tropical Pacific are also seen (Fig. 10). The significant downward motions occur over the NTA associated with the anomalous SST cooling, and result in surface northerly wind anomalies in summer. Due to the air mass convergence, the upward motions appear over the southeastern tropical Pacific, which are helpful for warm SST anomalies in the eastern tropical Pacific. Such meridional circulations across the tropical Atlantic and Pacific are not seen in autumn in model experiments.

The resultant warm SST anomalies from the two abovementioned pathways in the central and eastern Pacific could alter the Indo-Pacific Walker circulation in summer and autumn (Fig. 11). The NTA-induced ascending and descending branches are located on the central tropical Pacific and eastern Indian Ocean respectively. The latter induces lowerlevel easterly wind anomalies near the Sumatra coast in summer and autumn (Figs. 9, 11). The easterly wind anomalies 


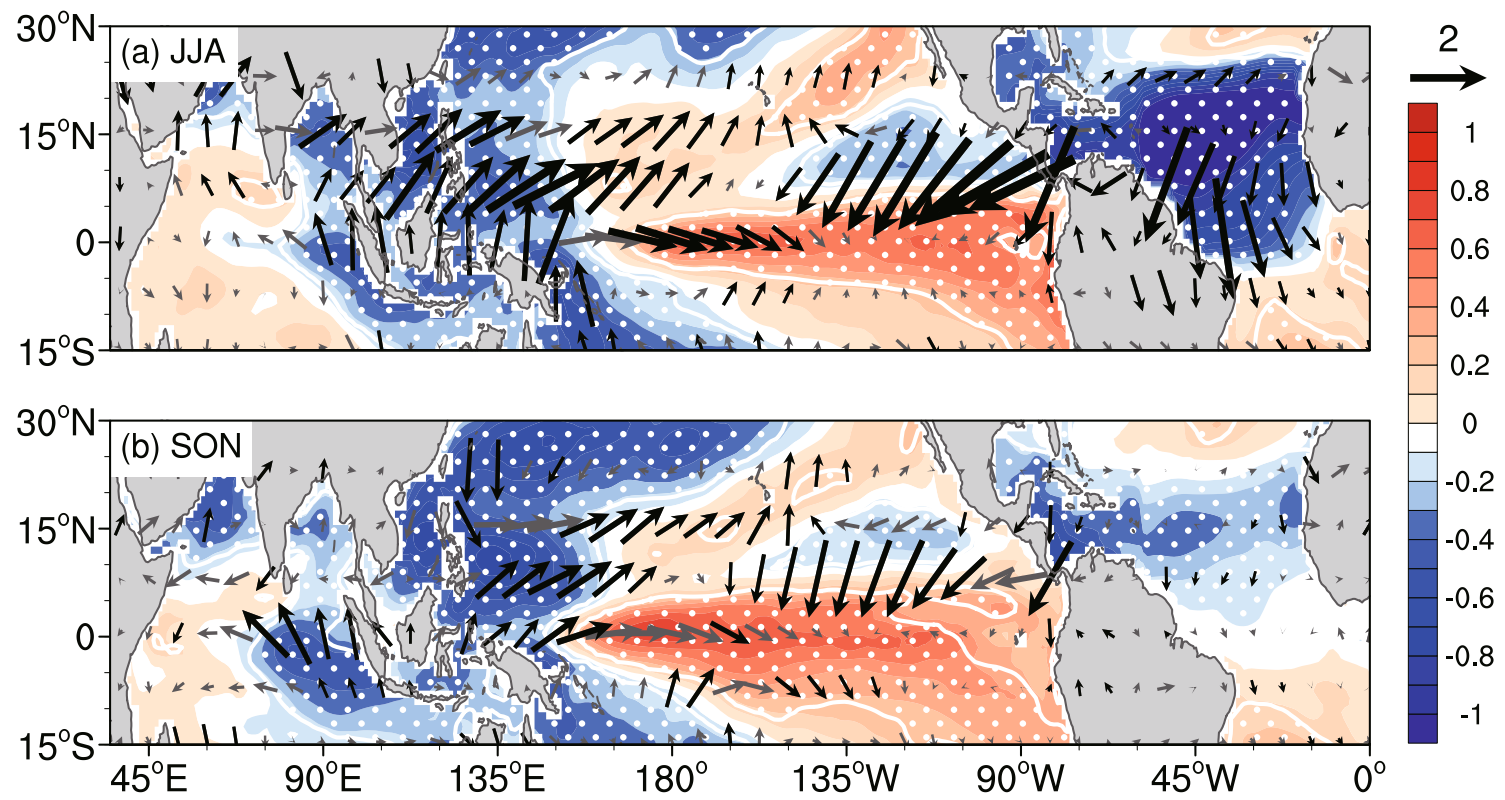

Fig. 9 Ensemble mean differences (CTRL_run minus NTA_run) of SST $\left({ }^{\circ} \mathrm{C}\right.$, shading) and 992-hPa wind ( $\mathrm{m} \mathrm{s}^{-1}$, vector) in a JJA and b SON seasons. The dotted regions and black vectors indicate confidence levels exceeding $90 \%$ based on Student's $t$ test

Fig. 10 Ensemble mean differences (CTRL_run minus NTA_run) of vertical-meridional circulation anomalies with meridional winds $\left(\mathrm{m} \mathrm{s}^{-1}\right)$ and vertical velocity (scaled by $-100 \mathrm{~Pa} \mathrm{~s}^{-1}$ ) along $150^{\circ}-20^{\circ} \mathrm{W}$ in the $\mathbf{a}$ JJA and $\mathbf{b}$ SON seasons. The black vectors indicate confidence levels exceeding $90 \%$ based on Student's $t$ test
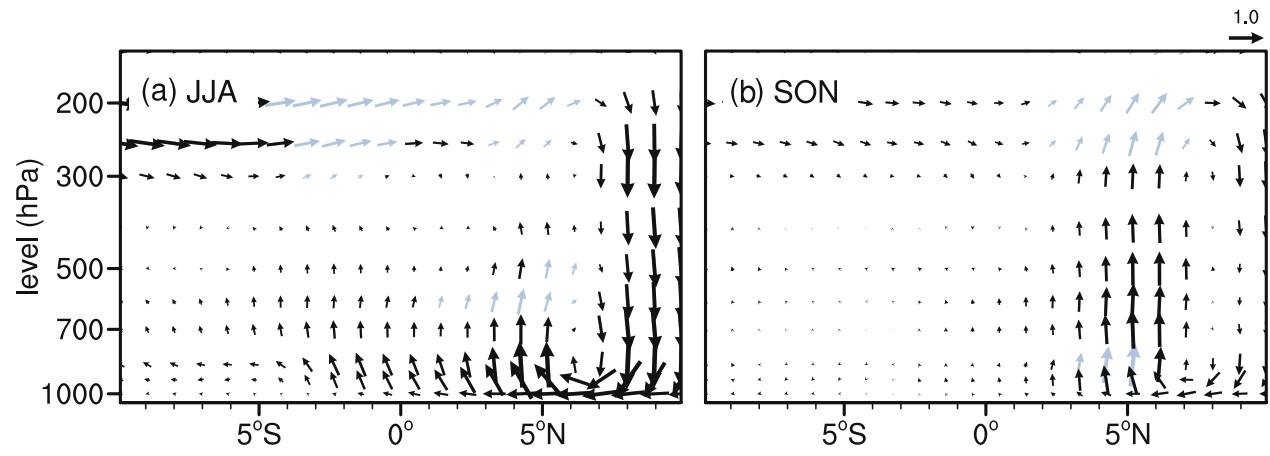

lift and depress the thermocline to the east and west tropical Indian Ocean (Fig. 12), enhancing the Bjerknes feedback over the tropical Indian Ocean. Thus, the differences between the CTRL_run and NTA_run demonstrate that the cooling NTA SST anomalies in spring and summer could lead to a positive IOD via large-scale circulation across three ocean basins and air-sea interactions (Fig. 9).

\section{Possible reasons why the impacts of NTA on the IOD were enhanced after the mid-1980s}

Previous studies illustrated the roles of internal decadal variability in modulating the relationships between two basins (Lim et al. 2017; Wang et al. 2017). Wang et al. (2017) pointed out that the positive phase of AMO could enhance the connection between the NTA and tropical 

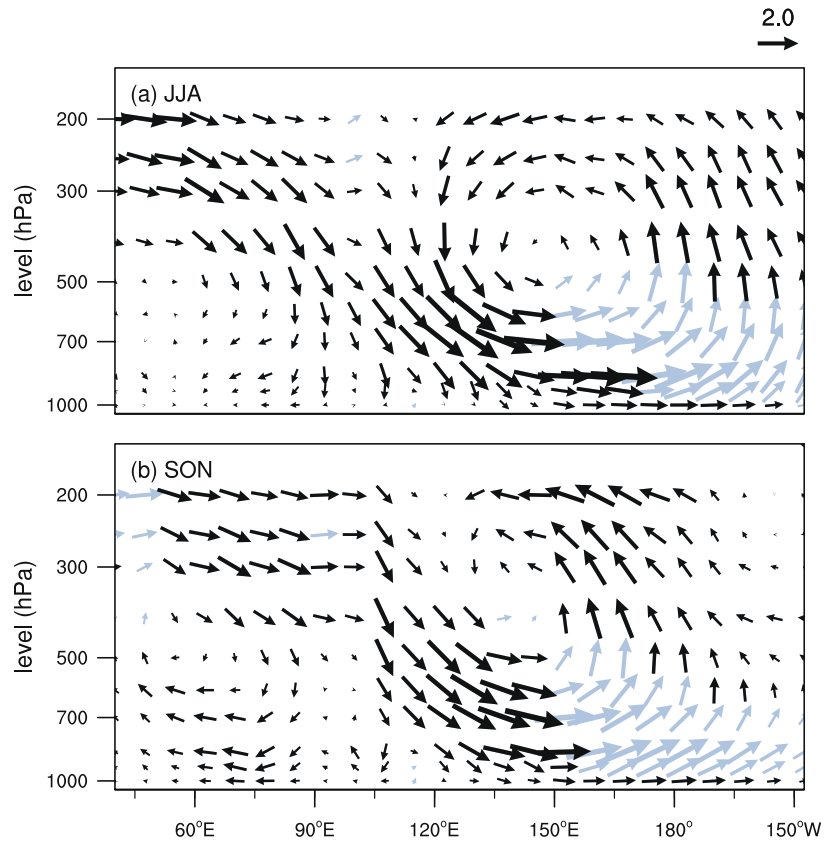

Fig. 11 Ensemble mean differences (CTRL_run minus NTA_run) of equatorial $\left(5^{\circ} \mathrm{S}-5^{\circ} \mathrm{N}\right)$ vertical-zonal circulation anomalies with zonal winds $\left(\mathrm{m} \mathrm{s}^{-1}\right)$ and vertical velocity (scaled by $-100 \mathrm{~Pa} \mathrm{~s}^{-1}$ ) in the a JJA and $\mathbf{b}$ SON seasons. The black vectors indicate confidence levels exceeding $90 \%$ based on Student's $t$ test
Pacific SST. During the warm phase of the Inter-decadal Pacific Oscillation (IPO), the ENSO-IOD relationship could become closer (Lim et al. 2017). Therefore, the roles of the AMO and IPO on the NTA-IOD relationship are firstly checked. It is found that the AMO and IPO indices show positive and negative phases after the mid1980s with close NTA-IOD relationship, indicating that the NTA-IOD relationship may not be modulated by the AMO and IPO (figure not shown).

Figure 13 illustrates the observed differences in SST mean states between the two periods. The tropical SSTs in the three basins after the mid-1980s are significantly warmer as high as $0.3{ }^{\circ} \mathrm{C}$ or above than those before the mid-1980s. Previous studies have suggested that the warmer SST in the Atlantic could enhance convection and precipitation in recent decades, enabling the Atlantic to influence other oceans (Li et al. 2016; Wang et al. 2017; Sun et al. 2017). Yuan et al. (2018) found that the IOD-ENSO teleconnection was stronger in the past century due to global warming. Therefore, it is assumed that the changes in the SST mean state under the context of global warming may be responsible for the enhancement of the relationship between the NTA and IOD after the mid-1980s.

To examine the hypothesis, two idealized coupled experiments named B1850_run and B2000_run are performed by using CESM 1.2.2. To simulate different climatological mean states, the external forcings (e.g., greenhouse gas,
Fig. 12 Longitude-time sections of ensemble mean differences (CTRL_run minus NTA_run) of thermocline depth $\left(20^{\circ} \mathrm{C}\right.$ isotherm depth, $\mathrm{m}$ ) averaged over $10^{\circ} \mathrm{S}-0^{\circ}$. The dotted regions indicate values exceeding the $90 \%$ confidence level based on Student's $t$ test

Fig. 13 Climatological annual mean SST $\left({ }^{\circ} \mathrm{C}\right)$ differences between 1950-1985 and 1986-2018 (1986-2018 minus 1950-1985). The dotted regions mean exceeding $90 \%$ confidence level based on Student's $t$ test
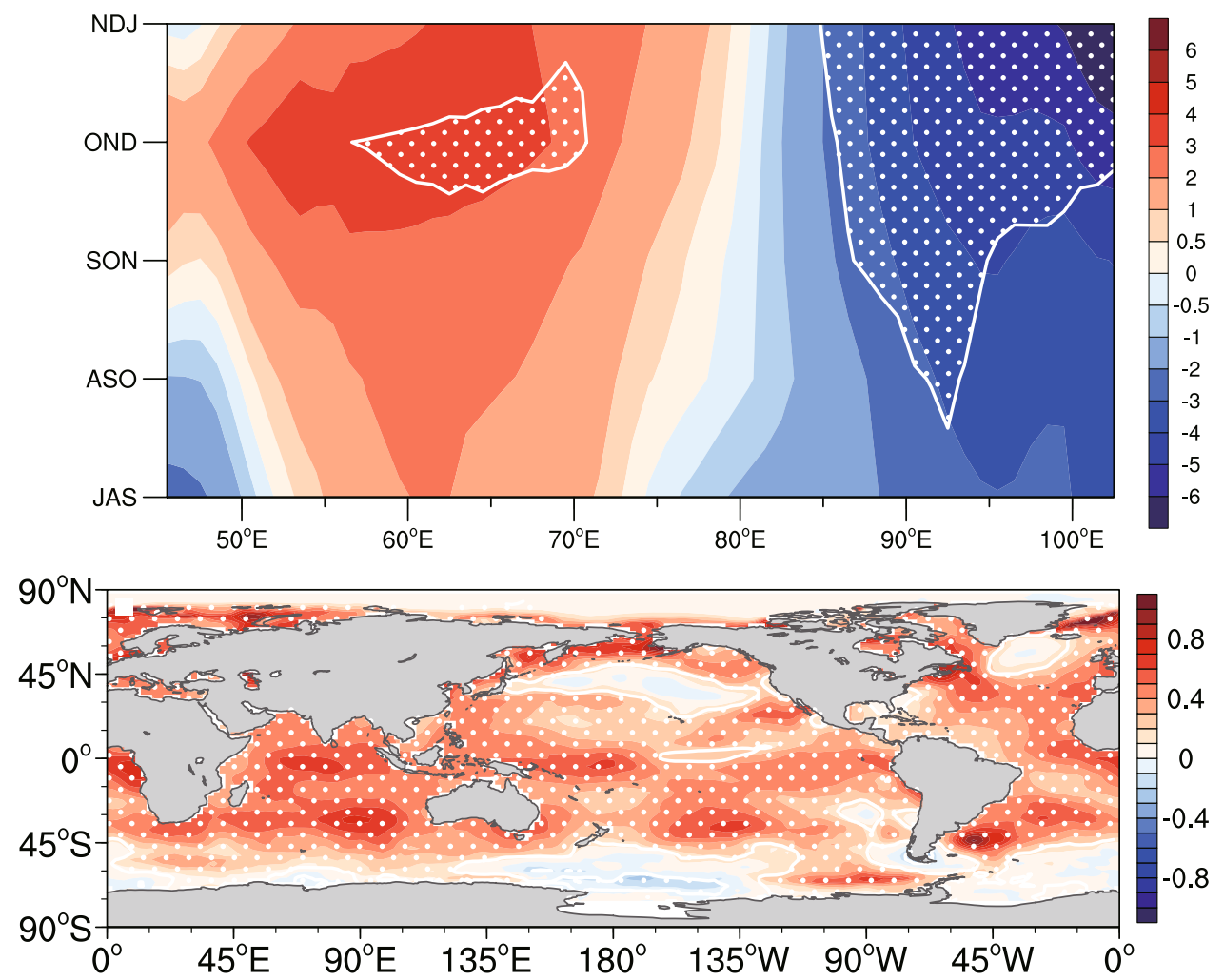
Fig. 14 a Climatological annual mean SST $\left({ }^{\circ} \mathrm{C}\right)$ differences between B2000_run and B1850_run during the years 251-350. b and $\mathbf{c}$ are composited anomalies (years that MAMJJ NTA SST anomalies exceed $1.5 \mathrm{std}$ ) of SST (shading) and 992-hPa wind (vector) anomalies in July-AugustSeptember-October (JASO) in B1850_run and B2000_run during the years 251-350, respectively. The influences of ENSO in spring are removed in the Indian Ocean and the Pacific in (b) and (c) by subtracting linear regression against the MAM Niño3.4 index. Dotted areas and black vectors in (b) and (c) indicate confidence levels exceeding $90 \%$ based on Student's $t$ test
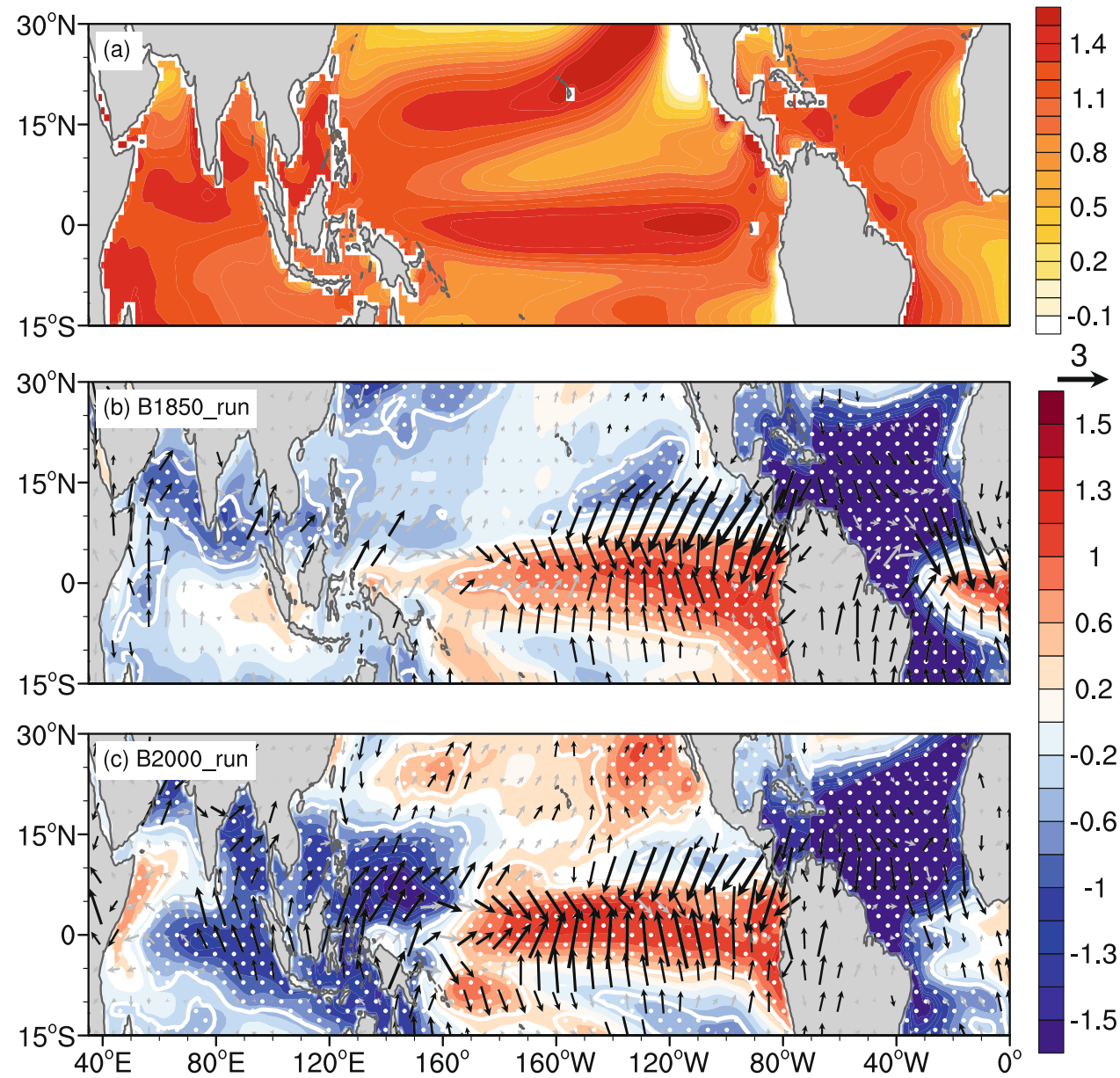

solar forcing and aerosol) are fixed at the levels in 1850 and 2000 in B1850_run and B2000_run, respectively. In two coupled experiments, free integration is carried out for 280 years, and the last stabilized 100 years are for analysis. Figure 14a shows the differences in annual mean SST over the three tropical oceans between B2000_run and B1850_ run. It is obvious that the annual mean SSTs in the tropics in the B2000_run are approximately $1.0{ }^{\circ} \mathrm{C}$ warmer than those in the B1850_run. The connections between the NTA SST anomalies and the IOD are thus compared between B2000_run and B1850_run.

Figure 14b, c present the composited SST and large-scale circulation anomalies averaged in June-August-September-October (JASO) for the years that MAMJJ NTA exceed its 1.5 std during the years of 251-350 (negative phases minus positive phases to present a positive IOD pattern) in B1850_run and B2000_run respectively. Similar to the observed results, the impacts of ENSO in the previous spring were removed first. The responses of SST anomalies and large-scale circulations in the Pacific and Indian Oceans to the cool SST anomalies in the NTA region are quite different between the two experiments. In the B1850_run, the cool SST anomalies in the NTA could induce strong meridional circulation over the NTA and the eastern tropical Pacific (Fig. 15a) and significantly lower-level wind convergence in the equator, which are helpful for the development of warm SST anomalies in the eastern tropical Pacific (Fig. 14b). These physical processes in B1850_run are similar to observed results before the mid-1980s (Fig. 5a-c), illustrating that the NTA SST anomalies influence the tropical Pacific through meridional circulation. It is noted that there are differences of meridional circulation associated with the cool NTA in B1850_run and the observed before the mid1980s. The anomalous meridional circulation is only located in the Northern Hemisphere in the B1850_run (Fig. 15a), while it extends to the Southern Hemisphere in the observation before the mid-1980s (Fig. 5a-c). Similar to the observed conditions before mid-1980, significant responses in the Indian Ocean are not observed to be accompanied by warm SST anomalies in the tropical Pacific in the B1850_ run (Fig. 14b).

For B2000_run, the significant responses in the Pacific and Indian Oceans to the cooling NTA are similar to the above results from the observations after the mid-1980s, in which an IOD-like pattern is seen (Figs. 4d-f, 14c). A cyclone at lower level is located over the western Pacific, 


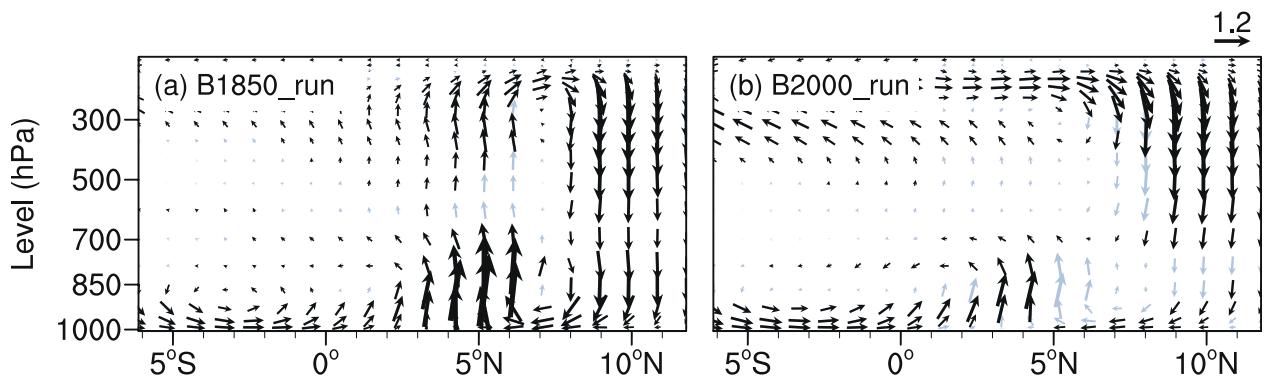

Fig. 15 Composited JASO mean meridional circulation anomalies of meridional winds and vertical velocity anomalies (scaled by -1 ) along $150^{\circ}-20^{\circ} \mathrm{W}$ for the years that MAMJJ NTAI exceed 1.5 std during 251-350 in a B1850_run and b B2000_run. The influences of
ENSO in spring are removed by subtracting linear regression against the MAM Niño3.4 index. The black vectors mean exceeding the $90 \%$ confidence level based on Student's $t$ test

mid-1980s. Before the mid-1980s, the relationship between them was rather weak, while a significantly negative relationship appeared after the mid-1980s, indicating that the cool SST anomalies in the NTA in spring could lead to a positive IOD in the following autumn. Due to the significant negative NTA-IOD relationship after the mid-1980s, spring NTA SST anomalies could be a useful predictor of the IOD except for ENSO which could continue to work under global warming.

The step-by-step physical processes connecting the tropical Atlantic, Pacific and Indian Oceans are checked to illustrate the mechanism of how the NTA influenced the IOD after the mid-1980s. A schematic diagram (Fig. 16) is given to show the responses over the tropical Pacific and Indian Ocean to the cool SST anomalies over the NTA in two periods. During the first period (Fig. 16a) the cool SST anomalies over the NTA change the inter-hemispheric meridional circulation between the NTA and southeastern tropical Pacific. The negative NTA SST anomalies induce descending motion which crosses the equator in surface and ascending motion over the tropical southeast Pacific. This southward flow turns into northwesterly anomalies due to Coriolis force, decreasing the southeasterly trade winds and enhancing SST. During the second period (Fig. 16b), the anticyclonic circulations locate over the Atlantic and North America, which result from a Gill-type Rossby-wave response excited by cool NTA SST anomalies. Due to teleconnection of Rossby-wave response, the cyclonic circulations appear in the west of the anticyclonic circulation over the subtropical northeastern Pacific. Such an atmospheric cyclonic circulation during spring-to-summer is favorable for the development of warm SST anomalies in the central and eastern tropical Pacific, which has been proved by CMIP5 model results (Wang et al. 2019).The anomalous lowerlevel southwesterlies between the anticyclonic and cyclonic circulations reduce the wind speed, and thus, warm SST anomalies appear and extend to the central tropical Pacific via WES feedback. In addition, the cyclonic circulations in ous spring-summer have been greatly enhanced since the 
Fig. 16 Schematic diagrams of physical processes of how the NTA SST anomalies influence the tropical Pacific and the IOD in a 1950-1985 and b 1986-2018. Shadings are SST anomalies. The brown vector lines are meridional or zonal circulations. The thicknesses of lines represent strengths of circulations. The black and green dotted ellipses indicate lowerlevel anticyclonic and cyclonic circulations, respectively
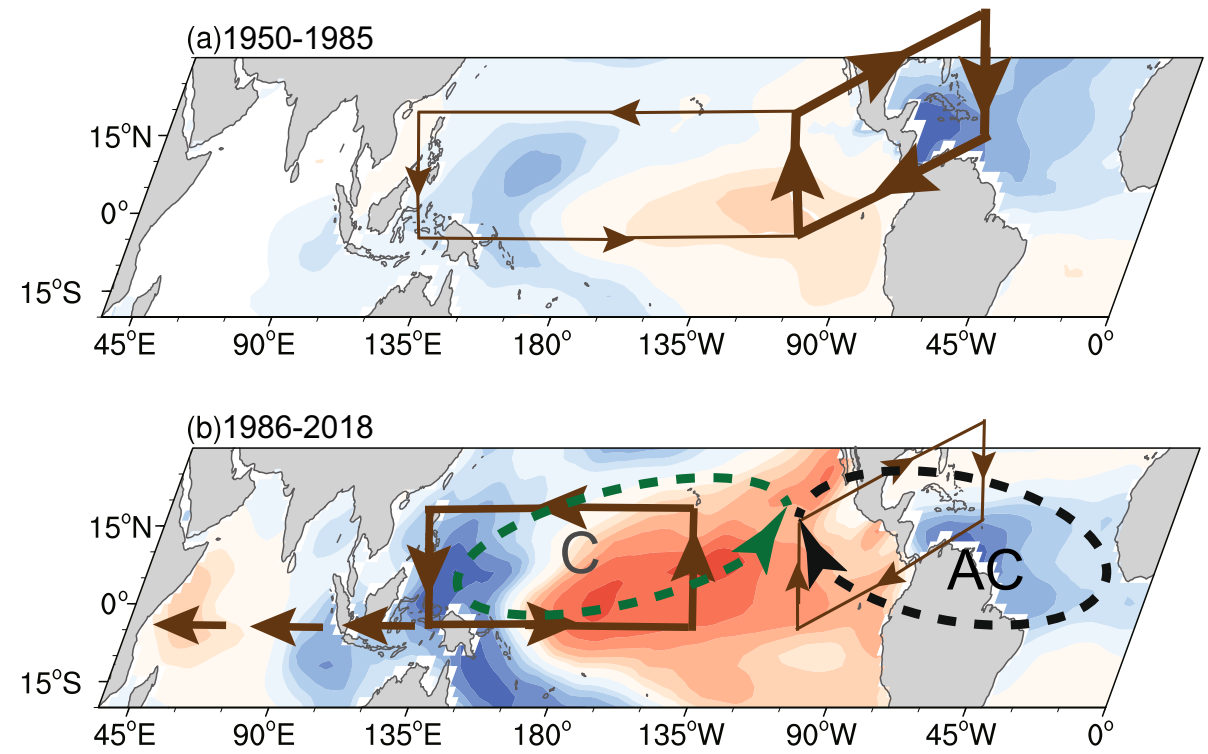

subtropical northeastern Pacific resulting from teleconnection of the Gill-type Rossby-wave response could induce the westerly wind anomalies in the south flank over the centralwestern Pacific, which favor the anomalous warm SST in the tropical Pacific. As the warm SST anomalies appear in the tropical Pacific, the Walker circulation over the tropical Pacific and Indian Ocean is altered. The sinking branch shifts westward around the Maritime Continent, inducing lower-level easterlies in the eastern tropical Indian Ocean and cold SST anomalies via thermocline feedback. Comparatively, the warm SST anomalies in the equatorial Pacific during the first period is relatively weak and the responses over the tropical Indian Ocean are not clear. Coupled model experiments with prescribed SSTs in the NTA confirm this chain of physical processes after the mid-1980s. Therefore, it is suggested that cool NTA SST anomalies could induce the IOD through cross-basin processes.

The present study also reveals why the NTA-IOD relationship becomes closer after the mid-1980s. In recent decades, under global warming, the surface temperature of global tropical oceans has been significantly warmer since the mid-1980s (Fig. 13). A pair of coupled experiments under different external forcing is conducted and compared, yielding the distinct background of SST in the tropics. It is shown that the cool NAT SST anomalies in spring could influence the IOD in the following autumn under the warmer mean state through the three-ocean interactions mentioned above.

One of the key physical processes of the NTA SST anomalies impacting the IOD is the connection between the tropical Atlantic and Pacific, which is one of the complex issues. Compared with the results of Park et al. (2019) analyzing the AWP and the tropical Pacific connections, both researches agreed that the warmer mean state of spring SST promotes the cross-basin climate impact since the mid-1980s via Gill response. However, different from Park et al. (2019), the present study suggested that the negative NTA SST anomalies could induce anomalous warm SST in the southeastern tropical Pacific via the local meridional circulation before the mid-1980s. In addition, Zhang et al. (2021) recently indicated that the NTA-ENSO relationship is a one-way Pacific to Atlantic connection, which is different from the present study and other previous researches (Ham et al. 2013; Wang et al. 2017; Ding et al. 2017). It means that the connections between the Pacific and Atlantic should be further studied.

Some studies found that the tropical Atlantic can directly influence the climate in the Indian Ocean. For example, the SST anomalies in the tropical Atlantic have considerable influence on the Indo-Western Pacific climate via an atmospheric Kelvin wave (Li et al. 2016; Takaya et al. 2021). Kucharski et al. (2008, 2009) and Wang et al. (2009) discovered that the Atlantic Niño could induce warming in the tropical western Indian Ocean and weakening of Indian summer monsoon rainfall. Thus, assessing the relative contributions of different mechanisms of the tropical Atlantic impacting the Indian Ocean climate will be analyzed in future studies.

Acknowledgements This study is supported by the Strategic Priority Research Program of Chinese Academy of Sciences (Grant Nos. XDB42000000 and XDA20060502), National Natural Science Foundation of China (Grant Nos. 41925024 and 41876021), and Key Special Project for Introduced Talents Team of Southern Marine Science and Engineering Guangdong Laboratory (Guangzhou) (GML2019ZD0306). Author Jiepeng Chen was supported by the Independent Research Project Program of State Key Laboratory of Tropical Oceanography (LTOZZ2005), the Guangdong Natural Science Foundation (2021A1515011368), Science and Technology Program of Guangzhou China (202102020384) and the Independent Research Project Program of State Key Laboratory of Tropical Oceanography 
(LTOZZ2005). Author Sheng Chen was supported by the National Natural Science Foundation of China (42006033). The numerical simulation work was supported by the High Performance Computing Division and HPC managers of Wei Zhou and Dandan Sui at the South China Sea institute of Oceanology, Chinese Academy of Sciences. This study is supported by China-Sri Lanka Joint Center for Education and Research, Chinese Academy of Sciences.

Open Access This article is licensed under a Creative Commons Attribution 4.0 International License, which permits use, sharing, adaptation, distribution and reproduction in any medium or format, as long as you give appropriate credit to the original author(s) and the source, provide a link to the Creative Commons licence, and indicate if changes were made. The images or other third party material in this article are included in the article's Creative Commons licence, unless indicated otherwise in a credit line to the material. If material is not included in the article's Creative Commons licence and your intended use is not permitted by statutory regulation or exceeds the permitted use, you will need to obtain permission directly from the copyright holder. To view a copy of this licence, visit http://creativecommons.org/licenses/by/4.0/.

\section{References}

Abram NJ, Gagan MK, Liu Z et al (2007) Seasonal characteristics of the Indian Ocean Dipole during the Holocene epoch. Nature 445:299-302. https://doi.org/10.1038/nature05477

Abram NJ, Gagan MK, Cole JE et al (2008) Recent intensification of tropical climate variability in the Indian Ocean. Nat Geosci 1:849-853. https://doi.org/10.1038/ngeo357

Alexander M, Scott J (2002) The influence of ENSO on air-sea interaction in the Atlantic. Geophys Res Lett. https://doi.org/10.1029/ 2001GL014347

Annamalai H, Murtugudde R, Potemra J et al (2003) Coupled dynamics over the Indian Ocean: spring initiation of the zonal Mode. Deep Sea Res II Top Stud Oceanogr 50:2305-2330. https://doi.org/10. 1016/S0967-0645(03)00058-4

Annamalai H, Potemra J, Murtugudde R, McCreary JP (2005) Effect of preconditioning on the extreme climate events in the tropical Indian Ocean. J Clim 18:3450-3469. https://doi.org/10.1175/ JCLI3494.1

Ashok K, Guan Z, Yamagata T (2003) Influence of the Indian Ocean dipole on the Australian winter rainfall. Geophys Res Lett 30:3-6. https://doi.org/10.1029/2003GL017926

Ashok K, Le CW, Motoi T, Yamagata T (2004) Decadal variability of the Indian Ocean dipole. Geophys Res Lett 31:1-4. https://doi. org/10.1029/2004GL021345

Baquero-Bernal A, Latif M, Legutke S (2002) On dipolelike variability of sea surface temperature in the tropical Indian Ocean. J Clim 15:1358-1368. https://doi.org/10.1175/1520-0442(2002)015\% 3c1358:ODVOSS\%3e2.0.CO;2

Behera SK, Luo JJ, Masson S et al (2006) A CGCM study on the interaction between IOD and ENSO. J Clim 19:1688-1705. https://doi. org/10.1175/JCLI3797.1

Cai W, Cowan T, Raupach M (2009) Positive Indian Ocean Dipole events precondition southeast Australia bushfires. Geophys Res Lett 36:1-6. https://doi.org/10.1029/2009GL039902

Cai W, Van Rensch P, Cowan T, Hendon HH (2012) An Asymmetry in the IOD and ENSO teleconnection pathway and its impact on australian climate. J Clim 25:6318-6329. https://doi.org/10.1175/ JCLI-D-11-00501.1

Cai W, Wu L, Lengaigne M et al (2019) Pantropical climate interactions. Science. https://doi.org/10.1126/science.aav4236
Cheng L, Trenberth KE, Fasullo J et al (2017) Improved estimates of ocean heat content from 1960 to 2015. Sci Adv. https://doi.org/ 10.1126/sciadv. 1601545

Clark CO, Cole JE, Webster PJ (2000) Indian Ocean SST and Indian summer rainfall: predictive relationships and their decadal variability. J Clim 13:2503-2519. https://doi.org/10.1175/15200442(2000)013\%3c2503:IOSAIS\%3e2.0.CO;2

Ding R, Li J, Seng Y et al (2017) Linking a sea level pressure anomaly dipole over North America to the central Pacific El Niño. Clim Dyn 49:1321-1339. https://doi.org/10.1007/s00382-016-3389-8

Du Y, Cai W, Wu Y (2013) A new type of the indian ocean dipole since the mid-1970s. J Clim 26:959-972. https://doi.org/10.1175/ JCLI-D-12-00047.1

Fang SW, Yu JY (2020) A control of ENSO transition complexity by tropical Pacific mean SSTs through tropical-subtropical interaction. Geophys Res Lett 47:1-9. https://doi.org/10.1029/2020G L087933

Guan Z, Yamagata T (2003) The unusual summer of 1994 in East Asia: IOD teleconnections. Geophys Res Lett 30:4-7. https://doi.org/ 10.1029/2002gl016831

Ham YG, Kug JS, Park JY, Jin FF (2013) Sea surface temperature in the north tropical Atlantic as a trigger for El Niño/Southern Oscillation events. Nat Geosci 6:112-116. https://doi.org/10.1038/ ngeo1686

Ham YG, Chikamoto Y, Kug JS et al (2017) Tropical AtlanticKorea teleconnection pattern during boreal summer season. Climate Dynamics 49:2649-2664. https://doi.org/10.1007/ s00382-016-3474-z

Huang B, Thorne PW, Banzon VF et al (2017) Extended reconstructed sea surface temperature, version 5 (ERSSTv5): upgrades, validations, and intercomparisons. J Clim 30:8179-8205. https://doi. org/10.1175/JCLI-D-16-0836.1

Hurrell JW, Holland MM, Gent PR et al (2013) The community earth system model: a framework for collaborative research. Bull Am Meteor Soc 94:1339-1360. https://doi.org/10.1175/ BAMS-D-12-00121.1

Kalnay E, Kanamitsu M, Kistler R et al (1996) The NCEP/NCAR 40-year reanalysis project. Bull Am Meteor Soc 77:437-471. https://doi.org/10.1175/1520-0477(1996)077\%3c0437:TNYRP\% 3e2.0.CO;2

Kao HY, Yu JY (2009) Contrasting Eastern-Pacific and Central-Pacific types of ENSO. J Clim 22:615-632. https://doi.org/10.1175/2008J CLI2309.1

Kim JW, An SI, Jun SY, Park HJ, Yeh SW (2017) ENSO and East Asian Winter monsoon relationship modulation associated with the anomalous Northwest Pacific anticyclone. Clim Dyn 49(4):1157-1179. https://doi.org/10.1007/s00382-016-3371-5

Kucharski F, Bracco A, Yoo JH, Molteni F (2008) Atlantic forced component of the Indian monsoon interannual variability. Geophys Res Lett. https://doi.org/10.1029/2007GL033037

Kucharski F, Bracco A, Yoo JH et al (2009) A Gill-Matsuno-type mechanism explains the tropical Atlantic influence on African and Indian monsoon rainfall. Q J R Meteorol Soc 135:569-579. https://doi.org/10.1002/qj.406

Li T, Wang B, Chang CP, Zhang Y (2003) A theory for the Indian Ocean dipole-zonal mode. J Atmos Sci 60:2119-2135. https://doi. org/10.1175/1520-0469(2003)060\%3c2119:ATFTIO\%3e2.0.CO;2

Li X, Xie SP, Gille ST, Yoo C (2016) Atlantic-induced pan-tropical climate change over the past three decades. Nat Clim Chang 6:275-279

Lim EP, Hendon HH, Zhao M, Yin Y (2017) Inter-decadal variations in the linkages between ENSO, the IOD and south-eastern Australian springtime rainfall in the past 30 years. Clim Dyn 49:97-112. https://doi.org/10.1007/s00382-016-3328-8

Lin C-Y, Yu J-Y, Hsu H-H (2015) CMIP5 model simulations of the Pacific meridional mode and its connection to the two types of 
ENSO. Int J Climatol 35:2352-2358. https://doi.org/10.1002/joc. 4130

Liu L, Yu W, Li T (2011) Dynamic and thermodynamic air-sea coupling associated with the Indian Ocean dipole diagnosed from 23 WCRP CMIP3 models. J Clim 24:4941-4958. https://doi.org/10. 1175/2011JCLI4041.1

Ma J, He W, Chen Z et al (2020) The impact of north tropical Atlantic sea surface temperature anomalies in the ensuing spring of El Niño on the tropical Indian Ocean and Northwest Pacific. Int J Climatol. https://doi.org/10.1002/joc.6500

McGregor S, Timmermann A, Stuecker MF et al (2014) Recent walker circulation strengthening and pacific cooling amplified by atlantic warming. Nat Clim Chang 4:888-892. https://doi.org/10.1038/ nclimate2330

Nuncio M, Yuan X (2015) The influence of the Indian Ocean dipole on Antarctic sea ice. J Clim 28:2682-2690. https://doi.org/10.1175/ JCLI-D-14-00390.1

Park JH, Li T, Yeh SW, Kim H (2019) Effect of recent Atlantic warming in strengthening Atlantic-Pacific teleconnection on interannual timescale via enhanced connection with the pacific meridional mode. Clim Dyn 53:371-387. https://doi.org/10.1007/ s00382-018-4591-7

Saji NH, Yamagata T (2003a) Structure of SST and surface wind variability during Indian Ocean dipole mode events: COADS observations. J Clim 16:2735-2751. https://doi.org/10.1175/15200442(2003)016\%3c2735:SOSASW\%3e2.0.CO;2

Saji NH, Yamagata T (2003b) Possible impacts of Indian Ocean dipole mode events on global climate. Clim Res 25:151-169. https://doi. org/10.3354/cr025151

Saji NH, Goswami BN, Vinayachandran PN, Yamagata T (1999) A dipole mode in the tropical Indian ocean. Nature 401:360-363. https://doi.org/10.1038/43854

Schott FA, Xie S-P, McCreary JP (2009) Indian Ocean circulation and climate variability. Rev Geophys 47:RG1002. https://doi.org/10. 1029/2007RG000245

Sun C, Kucharski F, Li J et al (2017) Western tropical Pacific multidecadal variability forced by the Atlantic multidecadal oscillation. Nat Commun. https://doi.org/10.1038/ncomms15998

Takaya Y, Saito N, Ishikawa I, Maeda S (2021) Two tropical routes for the remote influence of the northern tropical atlantic on the indowestern pacific summer climate. J Clim 34:1619-1634. https:// doi.org/10.1175/JCLI-D-20-0503.1

Vecchi GA, Soden BJ (2007) Global warming and the weakening of the tropical circulation. J Clim 20:4316-4340. https://doi.org/10. 1175/JCLI4258.1

Vimont DJ, Alexander M, Fontaine A (2009) Midlatitude excitation of tropical variability in the pacific: the role of thermodynamic coupling and seasonality. J Clim 22:518-534. https://doi.org/10. 1175/2008JCLI2220.1

Wang C (2019) Three-ocean interactions and climate variability: a review and perspective. Clim Dyn 53:5119-5136. https://doi.org/ 10.1007/s00382-019-04930-x

Wang C, Wang X (2013) Classifying el niño modoki I and II by different impacts on rainfall in southern China and typhoon tracks. J Clim 26:1322-1338. https://doi.org/10.1175/JCLI-D-12-00107.1

Wang X, Wang C (2014) Different impacts of various El Niño events on the Indian Ocean Dipole. Clim Dyn 42:991-1005. https://doi. org/10.1007/s00382-013-1711-2

Wang X, Li C, Zhou W (2006) Interdecadal variation of the relationship between Indian rainfall and SSTA modes in the Indian Ocean. Int J Climatol 26:595-606. https://doi.org/10.1002/joc.1283
Wang C, Kucharski F, Barimalala R, Bracco A (2009) Teleconnections of the tropical Atlantic to the tropical Indian and Pacific Oceans: a review of recent findings. Meteorol Z 18:445-454. https://doi. org/10.1127/0941-2948/2009/0394

Wang C, Lee SK, Mechoso CR (2010) Interhemispheric influence of the Atlantic warm pool on the Southeastern pacific. J Clim 23:404-418. https://doi.org/10.1175/2009JCLI3127.1

Wang C, Zhang L, Lee SK et al (2014) A global perspective on CMIP5 climate model biases. Nat Clim Chang 4:201-205. https://doi.org/ $10.1038 /$ nclimate 2118

Wang L, Yu JY, Paek H (2017) Enhanced biennial variability in the Pacific due to Atlantic capacitor effect. Nat Commun. https://doi. org/10.1038/ncomms14887

Wang X, Chen M, Wang C et al (2019) Evaluation of performance of CMIP5 models in simulating the North Pacific Oscillation and El Niño Modoki. Clim Dyn 52:1383-1394. https://doi.org/10.1007/ s00382-018-4196-1

Webster PJ, Moore AM, Loschnigg JP, Leben RR (1999) Coupled ocean-atmosphere dynamics in the Indian Ocean during 1997-98. Nature 401:356-360. https://doi.org/10.1038/43848

Xie SP, Philander SGH (1994) A coupled ocean-atmosphere model of relevance to the ITCZ in the eastern Pacific. Tellus A 46:340-350

Xie SP, Annamalai H, Schott FA, McCreary JP (2002) Structure and mechanisms of South Indian Ocean climate variability. J Clim 15:864-878. https://doi.org/10.1175/1520-0442(2002)015\% 3c0864:SAMOSI\%3e2.0.CO;2

Yang Y, Xie SP, Wu L et al (2015) Seasonality and predictability of the Indian Ocean dipole mode: ENSO forcing and internal variability. J Clim 28:8021-8036. https://doi.org/10.1175/JCLI-D-15-0078.1

Yeh S, Wang X, Wang C, Dewitte B (2015) On the relationship between the North Pacific climate variability and the Central Pacific El Niño. J Clim 28:663-677. https://doi.org/10.1175/ JCLI-D-14-00137.1

Yin X, Zhou LT (2019) An interdecadal change in the influence of the Central Pacific ENSO on the subsequent north tropical Atlantic spring SST variability around the mid-1980s. Clim Dyn 53:879893. https://doi.org/10.1007/s00382-019-04618-2

Yu JY, Kao HY (2007) Decadal changes of ENSO persistence barrier in SST and ocean heat content indices: 1958-2001. J Geophys Res Atmos 112:1-10. https://doi.org/10.1029/2006JD007654

Yu J, Li T, Tan Z, Zhu Z (2016) Effects of tropical North Atlantic SST on tropical cyclone genesis in the western North Pacific. Clim Dyn 46:865-877. https://doi.org/10.1007/s00382-015-2618-x

Yuan D, Wang J, Xu T et al (2011) Forcing of the Indian ocean dipole on the interannual variations of the tropical Pacific ocean: roles of the Indonesian through flow. J Clim 24:3593-3608. https://doi. org/10.1175/2011JCLI3649.1

Yuan D, Zhou H, Zhao X (2013) Interannual climate variability over the tropical pacific ocean induced by the Indian Ocean dipole through the Indonesian through flow. J Clim 26:2845-2861. https://doi.org/10.1175/JCLI-D-12-00117.1

Yuan D, Hu X, Xu P et al (2018) The IOD-ENSO precursory teleconnection over the tropical Indo-Pacific Ocean: dynamics and longterm trends under global warming. J Oceanol Limnol 36:4-19. https://doi.org/10.1007/s00343-018-6252-4

Zhang W, Jiang F, Stuecker MF et al (2021) Spurious north tropical Atlantic precursors to El Niño. Nat Commun 12:3096. https://doi. org/10.1038/s41467-021-23411-6

Publisher's Note Springer Nature remains neutral with regard to jurisdictional claims in published maps and institutional affiliations. 